\title{
Medical Stakeholders' Views on the Use of Packaged Charging Based on the Diagnosis-Related Group (DRG) in the Proposed Healthcare Reform
}

\author{
Fiona Y. Y. Wong ${ }^{*}$, Frank W. K. Chan, Su Liu
}

The Jockey Club School of Public Health and Primary Care, The Chinese University of Hong Kong, Hong Kong, China. Email: *fionawong1@gmail.com, cwkfrank@cuhk.edu.hk, sliu@cuhk.edu.hk

Received November $7^{\text {th }}, 2013$; revised December $5^{\text {th }}, 2013$; accepted December $26^{\text {th }}, 2013$

Copyright (C) 2013 Fiona Y. Y. Wong et al. This is an open access article distributed under the Creative Commons Attribution License, which permits unrestricted use, distribution, and reproduction in any medium, provided the original work is properly cited. In accordance of the Creative Commons Attribution License all Copyrights (C) 2013 are reserved for SCIRP and the owner of the intellectual property Fiona Y. Y. Wong et al. All Copyright (C) 2013 are guarded by law and by SCIRP as a guardian.

\begin{abstract}
The second stage consultation of healthcare reform in Hong Kong was launched in late 2010. One of the key features in the healthcare reform is the use of packaged charging based on Diagnosis-Related Group (DRG) structure, for reimbursement of medical fees in order to enhance cost certainty and transparency in private healthcare services. The objective of the study was to investigate the comments, concerns and suggestions of medical practitioners and private hospitals about medical pricing based on DRG. A survey completed by 1100 medical practitioners, seven focus groups with 42 medical practitioners and six hospital administrators participated was conducted. Generally, the participants believed that DRG was more applicable to straight-forward and one-off treatment procedures. Those working in the private sector and non-Family Medicine specialists were more concerned about the desirability and feasibility of DRG, and the potential of control of pricing in private market. The practice of DRG-based pricing method in certain specialties and cases which required multiple examinations and procedures for diagnosis were discussed. Concerns about doctors' selection of cases, upcoding and gaming on the charging system, as well as the high administration cost were also raised.
\end{abstract}

Keywords: Diagnosis-Related Group; Hospital Charges; Prospective Payment; Healthcare Reform

\section{Introduction}

The Hong Kong healthcare system is a dual system. It has a public sector and a private sector. Around $70 \%$ of outpatient care and primary care are provided largely by private sector and $78 \%$ of specialist and inpatient seconddary and tertiary care are delivered through the public sector [1]. Healthcare services in the public sector are heavily subsidized by the government. $97 \%$ of in-patient services in public hospitals are subsidized by the government [2]. With the growing demand of health services as a result of aging population, advancement of medical technology and rising medical costs, the existing healthcare system and delivery models need to be reformed in order to meet people's needs.

The current healthcare reform in Hong Kong was first

"Corresponding author. launched in 2008 of which improvements and resources had been invested in public healthcare services, healthcare infrastructure and safety net [3]. In October 2010, the second stage consultation of the healthcare reform was launched with a Health Protection Scheme (HPS) formulated [4]. The HPS is a voluntary and supplementary healthcare financing scheme regulated by the government. It aims to ease the pressure on the public healthcare system by encouraging more people to use private healthcare on a sustained basis. One of the key features of the HPS is the use of packaged charging based on the Diagnosis-Related Group (DRG) structure, for reimbursement of medical fees. The government believed that the packaged charging system would enhance cost certainty and transparency to consumers in using private healthcare services. However, the perspectives of general practitioners and specialists, especially those working in 
the private sector, are not clear.

The design and development of the original DRG began in the late 60s in the US [5]. In 1983 Congress started to enact a DRG based prospective payment system (PPS) for all Medicare patients. Later, a number of states and large payers also implemented DRG based hospital PPS for non-Medicare patients. The concept of DRG is to group patients into categories with homogeneous resource consumptions and similar clinical characteristics. DRG provides prospective payment based on the average cost of patients regardless of the actual costs in managing a patient within a DRG [6]. Patients are generally classified based on clinical data (diagnoses and procedures), demographics (gender and age), and resource consumption (length of stay and other costs). The DRG concept has also been adopted in Australia, Europe and Asia countries for reimbursement of inpatient care, healthcare financing and hospital management [7]. It is expected that DRG can strengthen the capacity for effective management, create strong incentives for discouraging unneeded services and improve the quality of medical care $[8,9]$. However, concerns on the impact of DRG on the quality of healthcare services have been raised in countries implementing DRG. Some specialties, for example, dermatology, and cases involving advanced and evolving therapeutics modalities or multiple procedures, could be underpaid if reimbursed by DRG [8]. In the US, for example, the new technology add-on payment policy is used to provide additional payments for cases with high costs involving eligible new technologies [10]. If the actual costs of the new technology case exceed the DRG payment by more than the estimated costs of the new technology, Medicare payment will be limited to the DRG payment plus $50 \%$ of the estimated costs of the new technology. In such circumstances, case selection of healthcare providers can happen, and patients with complicated health conditions may be rejected for treatment $[8,11]$. Other concerns, such as the quality of coding like the completeness of the coding system in capturing all the diagnoses and procedures, correctness in reflecting the diagnoses and treatment, and ensuring the codes, up to date have also been raised [12]. The principal diagnosis can be any condition present at admission that requires a hospital stay and further treatment. Moreover, to maximize reimbursement, patients may be assigned with hospital discharge diagnostic codes in a way that would increase payment to hospitals [13,14]. Some hospitals are also suspected to pre-discharge patients in order to control patients' length of stay [15].

In Hong Kong, the government proposed a government-regulated, voluntary HPS using packaged charging based on DRG for reimbursement of medical fees in its future healthcare reform. However, the specific DRG design is largely unknown, so are the perspectives of service providers. As secondary and tertiary health services are primarily delivered by the public sector, providers in the public and private sectors may have different concerns or their concerns could be different from those raised in other countries. The objective of this study was to investigate the comments, concerns and suggestions of medical practitioners and private hospitals about medical pricing based on DRG.

\section{Methodology}

There were two phases in the study using both quantitative and qualitative approaches. The first phase was a survey and the second phase was a focus group discussion. The survey helped understanding the general perspectives of the medication practitioners while in the focus group discussion, the rationales and reasons behind were investigated in depth.

\subsection{Procedures}

The survey was sent to all western medical practitioners listed in the up-to-date registration obtained from the Medical Council of Hong Kong on 23 December, 2010. In total, questionnaires were mailed to 11,890 doctors, whose names were listed in full registration (resident list only), limited registration, or specialist registration. Doctors with limited registration possess qualifications outside Hong Kong and they may teach, conduct research and/or perform hospital work only. Those with specialist registration have been awarded a Fellowship of the Hong Kong Academy of Medicine (HKAM) or certified by the HKAM that they have achieved a professional standard comparable to that recognized by the HKAM for the award of its fellowship. Registered medical practitioners who were non-residents, with provisional registration and temporary registration were excluded. A cover letter explaining the purpose of the study and an assurance of confidentiality was enclosed with the questionnaire, together with a prepaid, self-addressed envelope to facilitate reply of the completed questionnaire. Reminder letter and a copy of the questionnaire were first sent to those who had not responded after 14 days. A second reminder was sent out after another two weeks, followed by a telephone reminder to those with contact numbers available on the Hong Kong Doctors website

(www.hkdoctors.org), maintained by the Hong Kong Medical Association.

For the focus group discussion, seven homogenous focus groups with nine residents working in public sector (1 group), eight academics/college fellows (1 group), six private hospital residents (1 group), six private general practitioners (1 group), ten private specialists (2 groups), 
and six private hospital administrators (1 group) were formed. Participants were recruited by the snowball sampling method and professional network. Doctors who indicated in the survey that they were interested to participate in the focus group discussion were also invited.

A few days before each focus group, a stimulus was sent to the participants. At the beginning of each focus group discussion, the purpose and procedures of the focus group were explained and the written informed consent was obtained from each of the participants. The moderator led the discussion based on a semi-structured discussion guide. The participants were encouraged to express their views freely. Addition to the focus groups, three in-depth telephone interviews with private specialists were also conducted because they were unable to attend the private specialist focus groups. Proceedings were audio-recorded and transcribed verbatim.

\subsection{Instruments}

The questionnaire comprised two questions on the awareness about the HPS and the ongoing healthcare reform, four questions on the DRG-based charging in the HPS and, eight questions on demographic and practice-related details of respondents. A brief description of DRG-based charging was also enclosed for the reference of the respondents.

For the focus group discussions, a stimulus with background information on the health protection scheme, diagnosis-related groups, and a semi-structured discussion guide were prepared to facilitate the focus group discussions. The semi-structured discussion guide consisted of open ended questions focusing on views of the impact of DRG-based charging, feasibility of DRG-based charging, and alternative measures and opinions that can better enable the HPS to function effectively. The stimulus and discussion guide were pilot tested and refined before conducting the main focus groups.

\subsection{Data Analysis}

SPSS (Statistical Package for the Social Sciences Software) was used for data analysis. Demographic and practice-related details in the survey were analyzed using descriptive statistics. Measures on DRG-based charging were cross-tabulated with independent background variables. Statistically significant level was $5 \%$.

A five-stage data analysis in framework approach was used in the analysis of the focus group discussions: Familiarization, Identifying a thematic framework, Indexing, Charting, and Mapping and interpretation [16]. The transcripts were analyzed independently by two investigators using the NVivo 7 software (QSR International Pty. Ltd. (C1999-2006). Broad themes were first identi- fied. Each theme was assigned to a topic category based on its content. Categories were further divided into subcategories where appropriate, creating a tree-diagram. The two investigators discussed and examined the transcripts for connections among these themes until consensus was reached. The master framework was applied to all the transcripts. Interpretations of the themes were illustrated by extracts from the transcripts.

\subsection{Ethical Consideration}

This study was approved by the Ethics Committees of the Faculty of Medicine, The Chinese University of Hong Kong. The study was performed in accordance with the World Medical Association's Declaration of Helsinki.

\section{Results}

\subsection{The Survey}

A total of 1100 surveys were completed. $72.5 \%$ of the respondents were male and $27.8 \%$ aged $41-50$ years (Table 1). $88.1 \%$ were working full-time, $46.3 \%$ were working in public sector, followed by $44.4 \%$ working in private clinics. Among those working in the private sector, the majority $(69.3 \%)$ were solo practitioners. $65.4 \%$ of the participants identified themselves as specialists, including $5.8 \%$ in family medicine. The majority (76.5\%) obtained their basic medical degree in Hong Kong. Compared with the 2009 health manpower survey conducted by the Department of Health of Hong Kong [17] (which was a voluntary survey with a response rate of $69.8 \%$ ), the demographic and other relevant profiles of this survey respondents showed similar patterns.

\subsubsection{Awareness about the HPS and the Healthcare Reform}

Using a scale of $0-10(0=$ not aware or comprehend at all, $5=50 \%$ of its content, and $10=$ comprehend $100 \%$ of its content), 994 respondents self-rated their knowledge of the HPS and healthcare reform. Most respondents $(38 \%)$ rated $4-6$ with a mean score of 4.7 and a median of 5.0, which indicated that on average, they comprehended slightly less than $50 \%$ of the content of the HPS and healthcare reform.

\subsubsection{Feasibility of DRG-Based Charging}

$50.7 \%$ of the respondents agreed that it is feasible for healthcare services providers to set charges for common treatments/procedures based on DRG. $27.7 \%$ were neutral and $21.6 \%$ disagreed with the feasibility of DRGbased charging (Table 2). Public non-Family Medicine (non-FM) specialists agreed with the feasibility of DRG the most $(52.0 \%)$ followed by private GP and FM specialist $(50.0 \%)$. Most of the opponents were from private 
Table 1. Distribution of survey respondents, by demographics and key characteristics.

\begin{tabular}{|c|c|}
\hline & $\begin{array}{c}\text { \% of } \\
\text { Respondents }\end{array}$ \\
\hline \multicolumn{2}{|l|}{ Age (y) } \\
\hline 30 or below & $20.1 \%$ \\
\hline $31-40$ & $14.1 \%$ \\
\hline $41-50$ & $27.8 \%$ \\
\hline $51-60$ & $18.9 \%$ \\
\hline 60 or above & $19.2 \%$ \\
\hline \multicolumn{2}{|l|}{ Gender } \\
\hline Male & $72.5 \%$ \\
\hline Female & $27.5 \%$ \\
\hline \multicolumn{2}{|l|}{ Work } \\
\hline Full time & $88.1 \%$ \\
\hline Part time & $7.1 \%$ \\
\hline Not actively practicing & $4.9 \%$ \\
\hline \multicolumn{2}{|l|}{ Currently working in (multiple options allowed) ${ }^{*}$} \\
\hline Hospital Authority or government departments & $46.3 \%$ \\
\hline $\begin{array}{l}\text { Private clinics (except those under private } \\
\text { healthcare organizations) }\end{array}$ & $37.7 \%$ \\
\hline $\begin{array}{l}\text { Private clinics under private healthcare } \\
\text { organizations }\end{array}$ & $6.7 \%$ \\
\hline Private hospitals & $9.8 \%$ \\
\hline Universities & $4.6 \%$ \\
\hline Others & $5.1 \%$ \\
\hline \multicolumn{2}{|l|}{$\begin{array}{l}\text { Best describe your current job } \\
\text { (For those who are working in the private sector) }\end{array}$} \\
\hline Engaged in group practice as partner & $11.3 \%$ \\
\hline Engaged in group practice as non-partner & $13.3 \%$ \\
\hline As solo practitioner in private sector & $69.3 \%$ \\
\hline As resident doctor in private hospital(s) & $4.4 \%$ \\
\hline Others & $1.6 \%$ \\
\hline \multicolumn{2}{|l|}{ Type of job (multiple options allowed) ${ }^{* *}$} \\
\hline General practitioner & $27.7 \%$ \\
\hline Specialist in family medicine & $5.8 \%$ \\
\hline Specialist in clinical area & $54.7 \%$ \\
\hline Specialist in non-clinical area & $4.9 \%$ \\
\hline Others & $8.2 \%$ \\
\hline \multicolumn{2}{|l|}{ Basic medical degree obtained in } \\
\hline Hong Kong & $76.5 \%$ \\
\hline Overseas & $18.9 \%$ \\
\hline Mainland China & $4.60 \%$ \\
\hline \multicolumn{2}{|l|}{ Workplace-specialty } \\
\hline Private GPs/FM Specialists & $23.6 \%$ \\
\hline Private Non-FM Specialists & $24.7 \%$ \\
\hline Public GPs/FM Specialists & $8.3 \%$ \\
\hline Public Non-FM Specialists & $35.2 \%$ \\
\hline Others & $8.2 \%$ \\
\hline
\end{tabular}

Note: ${ }^{*} 9.3 \%$ respondents chose more than one option as their current work place. ${ }^{* *} 1.7 \%$ respondents chose more than one option to describe their type of job.
Table 2. Feasibility of DRG-based charging

\begin{tabular}{lc}
\hline & \% of Respondents \\
\hline $\begin{array}{l}\text { Feasible for healthcare service } \\
\text { providers to set their charges for common }\end{array}$ & \\
treatment/procedures based on DRG & \\
Strongly agree & $4.0 \%$ \\
Agree & $46.7 \%$ \\
Neutral & $27.7 \%$ \\
Disagree & $15.3 \%$ \\
Strongly disagree & $6.3 \%$ \\
Percentage of hospital admissions and & \\
ambulatory procedures in their work & \\
feasible for DRG (n = 726) & \\
$0 \%$ & $3.0 \%$ \\
$1 \%$ - 24\% & $13.5 \%$ \\
$25 \%$ - 49\% & $17.1 \%$ \\
$50 \%$ - 74\% & $21.2 \%$ \\
$75 \%-99 \%$ & $8.8 \%$ \\
$100 \%$ & $3.9 \%$ \\
\hline
\end{tabular}

non-FM specialists of which $31.5 \%$ disagreed with the feasibility of DRG.

For the feasibility of applying DRG to hospital charges alone, to doctor fees alone and to all charges (hospital charges plus doctor fees), most of the respondents agreed or strongly agreed DRG to be applied to hospital charges alone $(53.2 \%)$, followed by all charges $(37.2 \%)$ and doctor fees alone (29.0\%). In other words, applying DRG to doctors fees alone had the highest disagreement $(42.8 \%)$, followed by all charges (39.2\%) and hospital charges alone $(23.1 \%)$. Among different types of doctors, public non-FM specialists had the highest agreement rate to all the three implementation options (hospital charges: $56.9 \%$; doctor fees: $31.2 \%$; all charges: $40.2 \%$ ) while private non-FM specialists had the highest disagreement on the three implementation options $(57.1 \% ; 31.3 \%$; $54.5 \%$ ) (Table 3).

\subsubsection{Hospital Admissions and Ambulatory Procedures Feasible for DRG-Based Charging} Among 1074 respondents who responded to this question, $21.5 \%$ stated that their work did not involve hospital admissions and ambulatory procedures and $10.9 \%$ did not know. Among the remaining 726 respondents, 33.9\% stated that at least $50 \%$ of their cases were feasible to DRG-based charging (Table 2). Generally, the DRG was more feasible to cases of the non-FM specialists, $45.1 \%$ of those worked in public sector stated that $50 \%-100 \%$ of their cases were feasible to DRG, followed by $37.3 \%$ of those worked in private sector (Table 4).

\subsection{Focus Group}

A total of 48 medical doctors, including six private hospital administrators participated in the focus groups. The majority $(72.9 \%)$ were male and $80.5 \%$ of the medical 
Table 3. Analysis on feasibility of DRG on three different implementations across different workplace/specialty.

\begin{tabular}{|c|c|c|c|}
\hline & $\begin{array}{c}\text { Agree/ } \\
\text { Strongly } \\
\text { Agree }\end{array}$ & Neutral & $\begin{array}{l}\text { Disagree/ } \\
\text { Strongly } \\
\text { Disagree }\end{array}$ \\
\hline \multicolumn{4}{|c|}{ 1. All Changes (hospital charges plus doctor fees) $(\mathrm{N}=1047)$} \\
\hline Private GPs/FM Specialists & $38.0 \%$ & $23.3 \%$ & $38.8 \%$ \\
\hline Private Non-FM Specialists & $30.4 \%$ & $15.2 \%$ & $54.5 \%$ \\
\hline Public GPs/FM Specialists & $35.2 \%$ & $31.8 \%$ & $33.0 \%$ \\
\hline Public Non-FM Specialists & $40.2 \%$ & $24.8 \%$ & $35.0 \%$ \\
\hline Others & $36.0 \%$ & $34.9 \%$ & $29.1 \%$ \\
\hline \multicolumn{4}{|c|}{ 2. Hospital charges alone (except doctor fees) $(\mathrm{N}=991)$} \\
\hline Private GPs/FM Specialists & $49.8 \%$ & $25.8 \%$ & $24.4 \%$ \\
\hline Private Non-FM Specialists & $51.4 \%$ & $17.3 \%$ & $31.3 \%$ \\
\hline Public GPs/FM Specialists & $55.3 \%$ & $25.9 \%$ & $18.8 \%$ \\
\hline Public Non-FM Specialists & $56.9 \%$ & $23.7 \%$ & $19.4 \%$ \\
\hline Others & $50.0 \%$ & $34.1 \%$ & $15.9 \%$ \\
\hline \multicolumn{4}{|l|}{ 3. Doctor fees alone $(\mathrm{N}=\mathbf{9 8 7})$} \\
\hline Private GPs/FM Specialists & $29.0 \%$ & $30.8 \%$ & $40.2 \%$ \\
\hline Private Non-FM Specialists & $26.3 \%$ & $16.6 \%$ & $57.1 \%$ \\
\hline Public GPs/FM Specialists & $29.4 \%$ & $36.5 \%$ & $34.1 \%$ \\
\hline Public Non-FM Specialists & $31.2 \%$ & $28.9 \%$ & $39.8 \%$ \\
\hline Others & $25.6 \%$ & $43.9 \%$ & $30.5 \%$ \\
\hline
\end{tabular}

Table 4. Analysis of feasibility to DRG to their work across different workplace/specialty.

\begin{tabular}{lccc}
\hline & $\begin{array}{c}0 \%-49 \% \\
\text { of cases }\end{array}$ & $\begin{array}{c}50 \%-100 \% \\
\text { of cases }\end{array}$ & $\begin{array}{c}\text { Not applicable } \\
\text { to my } \\
\text { work/Don't } \\
\text { know }\end{array}$ \\
\hline Private GPs/FM Specialists & $37.7 \%$ & $20.9 \%$ & $41.4 \%$ \\
Private Non-FM Specialists & $48.6 \%$ & $37.3 \%$ & $14.1 \%$ \\
Public GPs/FM Specialists & $31.0 \%$ & $26.4 \%$ & $42.5 \%$ \\
Public Non-FM Specialists & $26.2 \%$ & $45.1 \%$ & $28.6 \%$ \\
Others & $17.4 \%$ & $26.7 \%$ & $55.8 \%$ \\
\hline
\end{tabular}

doctors obtained their basic medical degree in Hong Kong. Most of them were in the specialty of medicine (18.8\%) and surgery (10.4\%), while $18.8 \%$ were general practitioners. The majority $(64.6 \%)$ were working in the private sector, $45.7 \%$ had relevant working experience of 21 years or more (Table 5).

Most of the participants considered that the objective of the HPS to increase price transparency on the private healthcare market was important. However, views were divided regarding whether and how far the promotion of DRG-based charging method was the suitable means to achieve the desired end. The discussion was analyzed by the desirability and feasibility perspectives.
Table 5. Demographics and characteristics of focus group participants.

\begin{tabular}{|c|c|}
\hline & $\begin{array}{c}N=48 \\
n(\%)\end{array}$ \\
\hline \multicolumn{2}{|l|}{ Gender } \\
\hline Male & $35(72.9 \%)$ \\
\hline Female & $13(27.1 \%)$ \\
\hline \multicolumn{2}{|l|}{ Professions } \\
\hline \multicolumn{2}{|l|}{ Specialist } \\
\hline Medicine & $9(18.8 \%)$ \\
\hline Pediatrics & $2(4.2 \%)$ \\
\hline Psychiatry & $2(4.2 \%)$ \\
\hline Family Medicine & $2(4.2 \%)$ \\
\hline Community Medicine & $1(2.1 \%)$ \\
\hline Accident \& Emergency & $1(2.1 \%)$ \\
\hline Surgery & $5(10.4 \%)$ \\
\hline Anesthesiology & $1(2.1 \%)$ \\
\hline Ear, Nose \& Throat & $2(4.2 \%)$ \\
\hline Obstetrics \& Gynecology & $4(8.3 \%)$ \\
\hline Oncology & $1(2.1 \%)$ \\
\hline Ophthalmology & $1(2.1 \%)$ \\
\hline Orthopedics & $1(2.1 \%)$ \\
\hline Plastic Surgery & $1(2.1 \%)$ \\
\hline General Practitioner & $9(18.8 \%)$ \\
\hline Hospital Administrator & $6(12.5 \%)$ \\
\hline \multicolumn{2}{|l|}{ Working Unit (Multiple Options Allowed) } \\
\hline Hospital Authority (HA) & $11(22.9 \%)$ \\
\hline Private Hospital & $15(31.3 \%)$ \\
\hline Private Clinic & $12(25.0 \%)$ \\
\hline Private Clinic Under Private Healthcare Organization & $6(12.5 \%)$ \\
\hline University & $8(16.7 \%)$ \\
\hline Insurance Company & $1(2.1 \%)$ \\
\hline Other Statutory Board and Physical Committee & $1(2.1 \%)$ \\
\hline \multicolumn{2}{|l|}{ Number of Years of Practice $(n=46)$} \\
\hline $1-5$ & $1(2.2 \%)$ \\
\hline $6-10$ & $4(8.7 \%)$ \\
\hline $11-15$ & $9(19.6 \%)$ \\
\hline $16-20$ & $11(23.9 \%)$ \\
\hline$\geq 21$ & $21(45.7 \%)$ \\
\hline Missing & 2 \\
\hline \multicolumn{2}{|l|}{ Place Where Medical Degree Obtained $(n=41)$} \\
\hline Hong Kong & $33(80.5 \%)$ \\
\hline Overseas & $8(19.5 \%)$ \\
\hline Missing & 1 \\
\hline Not applicable for Hospital Administrator & 6 \\
\hline
\end{tabular}

\subsubsection{Desirability}

Some participants thought that the adoption of DRG as the basis to charge patients for hospitalization and ambulatory procedures was in the right direction to increase price transparency and contain medical cost increase in the private healthcare market. They expected that DRGbased charging method would enable the patients to have a better prediction of the expenditure amount needed (and the amount of reimbursement and co-payment if they were insured). There was also an expectation that DRG would foster competitiveness of the private healthcare market in the long run.

"I think this is favourable for patients as (price) trans parency will be increased. Right now there are many criticisms on the lack of a ceiling price for medical fee. It 
is all up to the doctors to charge..." (Academics)

"If the charge is fixed and all-inclusive, the patient can be better prepared in advance about the budget while hospital billing also becomes easier." (Hospital administrator)

However, some participants objected to the promotion of DRG-based charging method in the private healthcare market because it was based on the misperception that the market was lack of transparency. They considered private healthcare charges reasonably transparent nowadays as the private hospital bills set out the charges by service items clearly. They also believed that price transparency could not lead to better medical cost containment. They thought that price setting should be left to free market to determine as in the case of other comercial activities.

"I definitely do not accept packaged pricing... The current charging practice is extremely transparent... When we ask the private hospitals about their charges, they can provide detailed breakdown by service item as fine as the charges for each meal, each injection and each medication, etc." (Private GP)

"As far as transparency and competitiveness are concerned, DRG does not necessarily fare better than itemized charging if the latter is done properly." (Private specialist)

\subsubsection{Feasibility}

Generally, the participants believed that the implementation of DRG-based charging method would be technically challenging in practice and might involve complex issues to resolve, including assignment of DRG codes, applicability to complicated and uncertain cases and price setting mechanism.

\section{1) Assignment of DRG codes}

It was common that a patient presented with symptoms rather than a diagnosis before hospital admissions or ambulatory procedures. A single symptom might be the manifestation from an ailment disease to a serious condition. The participants believed that it would also be a challenge to use DRG codes on cases with multiple complications or comorbid conditions. Most of the time, patients might require a series of investigations before the diagnosis could be ascertained. Under these circumstances, the DRG code and hence the corresponding packaged charges might not be made known to the patients in the early instance, or only a rough estimation of medical charges could be provided to patients. As one of the objectives of the government to implement the DRG based charging is to increase the transparency of medical charges, some of the participants, especially the private specialists, doubted if this could be achieved.

"A case with glaucoma may turn out to have macular degeneration as well, and thus requires more treatments and procedures. Some cases are not that straight forward." (Private hospital specialist)

"It would be problematic to charge medical fees based on diagnosis. For example, stomach ache can be purely stomach ache, or it can be due to pneumonia or other problems... Medical fees in most countries are on procedure basis... There is no regulation of doctor's fees, though a reference price may be provided." (Private specialist)

2) Coding of complicated and clinical uncertain cases

It was commonly agreed that DRG-based charging was more applicable to simple, straight-forward and one-off treatment procedures. Although the principle of DRG is to set an average price for payment and reimbursement of medical cost, some participants raised their concerns about the actual practice of DRG-based charging as the resources for and cost of treatment could vary widely from one case to another. For some specialties like psychiatry, some of the participants believed that DRG-based charging might not be feasible. A relatively simple diagnosis might evolve into one with greater complication and co-morbidity during the course of hospitalization. Therefore, the participants expected that the future DRG coding system would be very refined so as to benchmark the charges for complicated and co-morbid cases appropriately.

"...For a straight forward operation, charging the same price for all cases is not an issue as long as the cost varies within a certain range. This spirit is acceptable under such a condition..." (Private specialist)

"For certain complicated diseases, chronic illnesses or cases with evolving complications, DRG is not feasible unless we adopt a complex set of DRG coding. It was once used in the United States, but it was infeasible for mental illness." (Private specialist)

\section{3) Price setting mechanism}

Participants were concerned about the criteria and mechanism used in determining the price of each DRG codes as patient heterogeneity is an important concern. The difference in age and health status could require different workloads in clinical management and hence substantial difference in the cost of care. Along with technological advancement, more choices of treatment at different cost levels were available to match with different patients' health condition and budget, however, DRG coding system might affect patients' choice of treatment. Because of the complexities inherent to the DRG coding system and its application in a private market setting, some participants anticipated that a lot of administrative resources would have to be deployed to establish a robust DRG-based coding system.

"For example, two different methods can be used to 
treat the same case, with one being more effective but more expensive. Under DRG, I cannot use the more expensive method if it is not included in the coding. This indirectly affects the choice of treatment." (Public hospital resident)

"We have to pay salaries for staffing, including the accountants. You have to count administration cost to arrive at the total cost of adopting DRG-based charging." (Private specialist)

\subsubsection{Other Factors Affecting the Feasibility of DRG-Based Charging}

Many participants revealed that factors like doctors' choices of cases, quality of healthcare, and gaming on the charging system, such as upcoding, could also affect the feasibility of DRG-based charging method.

1) Doctors' choices of cases

If the DRG coding system could not adequately allow for reasonable variation in cost associated with complexities, patients' health condition and other factors, it might present a degree of financial risk that a private doctor was unable to bear. In response, some doctors might refuse to offer DRG-based pricing and decline those patients who insisted on that, while some others might only be willing to offer DRG-based charging selectively to the cases that appeared to be simpler and straight forward.

"...only uncomplicated surgeries will be performed. This may result in some cases declined by (private) doctors... No (private) hospitals will admit them... Doctors may take up cases selectively." (Public hospital resident)

2) Quality of healthcare

Although the DRG-based charging levels were not the statutory ceilings, the private healthcare providers (including hospitals and doctors) might strive to compete in price and compromise on the quality of healthcare. For instance, there might be lesser volume of services and lower quality of medication and assessment within the package for the sake of cost saving.

"Private hospitals must strive to make profit. While patients go to private hospitals for the sake of treatments and services of better quality, (with DRG) they may end up receiving public-sector-type of service." (Private hospital resident)

"The problem with using packaged pricing is that the doctors may cut down on the investigation procedures. Take appendicitis as an example,... if the fee is limited to HK\$12,000 (US\$1558), the doctor may tend not to do MRI."(Private specialist)

3) Gaming on the charging system

Some participants mentioned that even if the normal charge for a case was less than the benchmark price level, private healthcare providers could still charge up to the benchmark or choose DRG code which reflects higher level of complexity when the dividing line was blurred. A further possibility was to discharge a patient from hospital prematurely and re-admit him/her shortly afterwards to justify a new episode and hence a new count of package.

"If you know the rules of this game, you will know which code comes with a higher price and change the diagnosis accordingly." (Private hospital specialist)

"If a doctor thinks that the cost of the case has exceeded the package charge, what will happen? The doctor could discharge the patient and then re-admit him/her, and the case would become a new admission with a new DRG." (Private GP)

\subsubsection{Other Alternative Measures and Opinions}

The participants also expressed their suggestions includeing, engaging medical stakeholders in developing the DRG-based pricing system, separation of packaged price for hospital and doctor services, and the issues in subsidizing patients who had higher medical service utilization.

"I think that the group most vulnerable to the impact of DRG was not consulted...No doctors have been involved in doing this piece (public consultation document)." (Private specialist)

"I strongly think that hospital charge and doctor's fee should be separated in a package...First, the fees are clear, and second, doctors can freely decide whether to participate in the scheme on a case by case basis." (Private specialist)

"... if everyone has to pay a higher premium because of packaged pricing to share out the cost, it is probably not that fair to those patients with less complicated problems." (Private GP)

\section{Discussion}

In both survey and focus group discussions, the participants were provided with information on HPS and DRGbased charging to help them to familiarize with the topics. However, the participants could still have different levels of understanding of DRG and prospective payment. The participants generally agreed that the DRG-based medical charging method was considerable to the healthcare system but had concerns on its feasibility. Most of the participants considered that the objective of the HPS to increase price transparency on the private healthcare market was important. However, views were divided among those working in public/academics and private sectors.

Medical practitioners who were non-FM specialists working in the private sector and administrators from private hospitals were relatively more concerned with 
both the desirability and feasibility of DRG because the DRG-based charging method was seen as a mechanism to control the health services fees the private medical practitioners charged their patients. They believed that price setting in the private sector should be left to free market as in the case of other commercial activities. There is also evidence that competition in free market is associated with improved clinical outcomes, reduced costs and more efficient system in some settings $[18,19]$. Medical practitioners working in academic or public sector were less affected as their income was not affected by the DRG-based medical charging method, therefore, both the findings of survey and focus group discussions revealed that the DRG-based medical charging system was more acceptable to them.

Because of the control of medical charging, the participants anticipated that there could be some negative impact on the accessibility of health services of patients. Our participants expressed their concerns about doctors' rejection of cases which were more complicated or those which required multiple procedures to avoid underpaid by DRG. Specialties like oncology and dermatology of which advanced and evolving therapeutic technologies are involved could also be underpaid by DRGs. Our participants stated that this could involve problems of containing cost by compromising on quality or pre-discharge of patients. If this is the case, these patients may have difficulties in accessing private healthcare services, and the goal of the government in promoting HPS to improve service quality and divert patients to the private sector may not be achieved. Patients with complexities will then need to seek services from the public hospitals. The burden of the public sector will definitely increase which will further worsen the existing financial and manpower issues in the public sector.

Doctors and researchers of other countries also have similar concerns as the participants in this study. In terms of controlling medical cost, studies found that the length of stay of patients with lower respiratory tract infection in DRG hospitals was found to be significantly shorter compared to fee-for-service hospitals [20] and women with breast cancer were also treated with shorter LOS for surgical therapy and chemotherapy [21]. Mortality analyses following hospitalization have been found to be unaffected by the introduction of DRG-based payment system [22]. However, whether DRG effectively reduces LOS without negatively affecting patient outcomes is still a matter of controversy [23]. A study evaluating the impact of DRG on the healthcare system in Germany found that doctors tempted to reduce their services or take action on early discharge and new admission in order to avoid underpaid, which was also a main concern of our participants [8]. Another study also reported a de- crease of the quality of care as seen from the patient perspective, especially their experience of staff treatment, after the implementation of DRG in two surgical clinics [24]. Besides refusing complex patients as the participants mentioned, there is also a possibility that hospitals with a more complex case mix will pass the costs associated with these complex patients to patients in lower cost DRGs [6].

In the U.S., improper payment review entities have been developed to prevent improper payments through upcoding, resolve discharge disputes between beneficiary and hospitals and to identify and measure other behaviors related to improper payments [25]. Because of the complexity of cases, and the necessity of monitoring and auditing the DRG coding, a mechanism or a system is also essential in Hong Kong to audit claims for correct DRG coding as well as prevent inappropriate behaviours such as refusing patients or early discharge. The proposed HPS in Hong Kong will implement a Health Insurance Claims Arbitration Mechanism to handle disputes over health insurance claims and audit claims for correct DRG coding, but the details of operation were not known at the time of the study.

Our participants also conveyed that the DRG-pricing method was not applicable to all clinical cases. No matter the participants were from public or private sector, specialists or non-specialists, they emphasized that cases which were admitted with a single symptom but later changed to a serious condition and those required a series of investigations before a diagnosis could be ascertained, were difficult to be assigned DRG codes. Therefore, if the purpose of the government of using DRG is to allow the patients to know the medical fees in advance and to enhance the transparency of healthcare cost, this could be difficult to achieve. Researchers have questioned whether DRGs can adequately adjust for severity because when a patient has multiple conditions, the sequence and choice of the codes may not be reliable [26]. Factors such as physical and cognitive impairment, poor nutrition, comorbidity as well as poly-pharmacy have to be considered when calculating resources use [27]. Some of the participants also raised concerns about managing psychiatric patients. The Centers for Medicare and Medicaid Services in the U.S. exempted psychiatric facilities from DRG-based charging for over two decades. A study on the implications of DRG for psychiatry found that there was little commonality of in-patient resource use and duration of stay among patients within a given psychiatric DRG [28]. DRGs were identified as poor predictors of resource utilization in psychiatric cases which could lead to inappropriate discharge of patients [29]. Until 2005 , a new prospective payment system has been implemented for inpatient psychiatry in the US [30]. If our 
government plans to cover inpatient psychiatry in the future, a very refined mechanism with adjustment factors like age, day of stay, electroconvulsive therapy [31] has to be set up to improve the accuracy for estimating the medical payment of psychiatry cases in advance. As our government has not yet provided any details on developing the DRG codes and the mechanisms for adjusting patient and clinical factors, it is understandable that the participants in the study perceived that DRG was more applicable to simple, straight-forward and one-off treatment procedures.

Time spent in administrative work as well as the administrative cost was also raised in the focus groups. Physicians in Germany had revealed their concerns of additional workload for coding and paper work [32]. Establishing a robust DRG-based charging system is a difficult and complicated task. To reflect and induce desirable technological change, DRGs have to be updated periodically. [33] Together with the arbitration mechanism for handling disputes and monitoring claims mentioned previously, these will all lead to high administrative cost. It was worried that if administration cost was prohibitive, the HPS might not be financially sustainable.

\section{Conclusion}

This is the first study in our region to study the concerns and perspectives of stakeholders from the medical sector on the DRG-based charging method. Participants were divided regarding the desirability and feasibility of DRG. Doctors working in the private sector and non-FM specialists were more concerned about the potential of control of pricing in private market. As regards feasibility, it would be technically challenging to practice DRG-based pricing method in certain specialties and clinical problems, and cases which require multiple examinations and procedures for diagnosis. The government should consider engaging medical stakeholders in the development of the DRG-based charging system, separation of packaged price for hospital and doctor services, and develop measures to minimize the equity issues in subsidizing patients with higher medical service utilization. If the government can carefully consider and tackle the technical concerns, it should be able to enhance the practicability of carrying out the proposed DRG-based pricing method.

\section{Acknowledgements}

We would like to thank the Food and Health Bureau of Hong Kong Special Administrative Region for supporting this study and all the medical practitioners and hospital administrators who participated in the survey and focus group discussion.

\section{REFERENCES}

[1] Census and Statistics Department, "Thematic Household Survey Report No. 50," Census and Statistics Department, Hong Kong SAR, 2013.

[2] Hospital Authority, “Annual Report 2010-2011,” Hospital Authority, Hong Kong SAR.

[3] Food and Health Bureau, Hong Kong SAR, "Your Health Your Life: Healthcare Reform Consultation Document," Food and Health Bureau, Hong Kong SAR, 2008.

[4] Food and Health Bureau, Hong Kong SAR, "My Health My Choice: Healthcare Reform Second Stage Consultation Document," Food and Health Bureau, Hong Kong SAR, 2010.

[5] R. F. Averill, J. H. Muldoon, J. C. Vertrees, N. I. Goldfield, R. L. Mullin, E. C. Fineran, et al., "The Evolution of Casemix Measurement Using Diagnosis Related Groups (DRGs)," 3M Health Information Systems Research Report 5-98, 1998.

[6] S. Saint, J. Rose, A. S. Lichter, S. Forrest and L. F McMahon, "Shifting Costs from High-Cost to Low-Cost Diagnosis-Related Groups?" Evaluation \& The Health Professions, Vol. 25, No. 3, 2002, pp. 259-269. http://dx.doi.org/10.1177/0163278702025003001

[7] F. H. Roger France, "Case Mix Use in 25 Countries: A Migration Success But International Comparisons Failures," International Journal of Medical Informatics, Vol. 70, No. 2, 2003, pp. 215-219. http://dx.doi.org/10.1016/S1386-5056(03)00044-3

[8] P. Hensen, T. Furstenberg, T. A. Luger, M. Steinhoff and N. Roeder, "Case Mix Measures and Diagnosis-Related Groups: Opportunities and Threats for Inpatient Dermatology," European Academy of Dermatology and Venereology, Vol. 19, No. 5, 2005, pp. 582-588. http://dx.doi.org/10.1111/j.1468-3083.2005.01258.x

[9] R. E. Mechanic, "Opportunities and Challenges for Episode-Based Payment," The New England Journal of Medicine, Vol. 365, No. 9, 2011, pp. 777-779. http://dx.doi.org/10.1056/NEJMp1105963

[10] CMS.gov., Centers for Medicare \& Medicaid Services, "New Medical Services and New Technologies." http://www.cms.gov/Medicare/Medicare-Fee-for-ServicePayment/AcuteInpatientPPS/newtech.html

[11] R. P. Ellis and T. G. McGuire, "Hospital Response to Prospective Payment: Moral Hazard, Selection, and Practice-Style Effects," Journal of Health Economics, Vol. 15, No. 3, 1996, pp. 257-277.

http://dx.doi.org/10.1016/0167-6296(96)00002-1

[12] L. von Brasch, "Implementing Diagnosis-Related Groups (DRGs)," EHMA Annual Conference, 2009. http://www.ehma.org/files/090625 EHMA_DRG_final.p $\mathrm{df}$

[13] H. Edelstein, "Correspondence: The Prospective Payment System and Discharge Diagnoses for Coronary Heart Disease," The New England Journal of Medicine, Vol. 330, 1994, pp. 578-579. http://dx.doi.org/10.1056/NEJM199402243300821

[14] A. R. Assaf, K. L. Lapane, J. L. McKenney and R. A. 
Carleton, "Possible Influence of the Prospective Payment System on The Assignment of Discharge Diagnoses for Coronary Heart Disease," The New England Journal of Medicine, Vol. 329, No. 13, 1993, pp. 931-935. http://dx.doi.org/10.1056/NEJM199309233291307

[15] Chinese Times, 2010. http://www.nstyle.url.tw/fina/index.php?option=com con tent\&task $=$ view\&id=544\&Itemid $=2$

[16] C. Pope, S. Ziebland and N. Mays, "Qualitative Research in Health Care: Analysing Qualitative Data," British Medical Journal, Vol. 320, 2000, pp. 114-116. http://dx.doi.org/10.1136/bmj.320.7227.114

[17] Department of Health, "Executive Summary of 2009 Health Manpower Survey on Doctors," DH, the Government of the Hong Kong Special Administrative Region, 2009.

http://www.dh.gov.hk/textonly/English/statistics/statistics _hms/files/sum dr09.pdf

[18] The Health Foundation Inspiring Improvement, "Competition in Healthcare," UK, 2011. http://www.health.org.uk/media_manager/public/75/Rese arch $\% 20$ scan $\% 20$ - $\% 20$ competition $\% 20$ in $\% 20$ healthcare $\% 20$ (April\%202011).pdf

[19] Medicare Payment Advisory Commission, "Chapter 8 Using Market Competition in Fee-for-Service Medicare," In: Report to the Congress: Variation and Innovation in Medicare, MedPAC, Washington DC, 2003, pp. 131-146. $\mathrm{http}: / /$ medpac.gov/publications/congressional_reports/Jun e03_Ch8.pdf

[20] P. Schuetz, W. C. Albrich, I. Suter, B. L. Hug, M. ChristCrain, T. Holler, et al., "Quality of Care Delivered by Fee-for-Service and DRG Hospitals in Switzerland in Patients With Community-Acquired Pneumonia," Swiss Medical Weekly, Vol. 141, 2011, Article ID: w13228.

[21] H. Kuwabara and K. Fushimi, "The Impact of a New Payment System with Case-Mix Measurement on Hospital Practices for Breast Cancer Patients in Japan," Health Policy, Vol. 92, No. 1, 2009, pp. 65-72. http://dx.doi.org/10.1016/j.healthpol.2009.02.010

[22] W. H. Rogers, D. Draper, K. L. Kahn, E. B. Keeler, L. V. Rubenstein, J. Kosecoff, et al., "Quality of Care before and after Implementation of the DRG-Based Prospective Payment System: A Summary of Effects," JAMA, Vol. 264, No. 15, 1990, pp. 1989-1994. http://dx.doi.org/10.1001/jama.1990.03450150089037

[23] B. H. Gilman, "Hospital Response to DRG Refinements: The Impact of Multiple Reimbursement Incentives on Inpatient Length of Stay," Health Economics, Vol. 9, No. 4, 2000, pp. 277-294.

http://dx.doi.org/10.1002/1099-1050(200006)9:4<277::AI D-HEC513>3.0.CO;2-1
[24] B. Ljunggren and P. Sjoden, "Patient Reported Quality of Care before vs. after the Implementation of a Diagnosis Related Groups (DRG) Classification and Payment System in One Swedish County," Scandinavian Journal of Caring Sciences, Vol. 15, No. 4, 2001, pp. 283-294. http://dx.doi.org/10.1046/j.1471-6712.2001.00046.x

[25] CMS CERT Team, "Medicare Fee-for-Service, 2012 Improper Payments Report," Centers for Medicare \& Medicaid Services, Baltimore, 2012.

http://www.cms.gov/Research-Statistics-Data-and-Syste $\mathrm{ms} /$ Monitoring-Programs/CERT/Downloads/MedicareFe eforService2012ImproperPaymentsReport.pdf

[26] M. A. Rosenberg and M. J. Browne, "The Impact of the Inpatient Prospective Payment System and DiagnosisRelated Groups: A Survey of The Literature," North American Actuarial Journal, Vol. 5, No. 4, 2001, pp. 8494. http://dx.doi.org/10.1080/10920277.2001.10596020

[27] S. E. Campbell, D. G. Seymour, W. R. Primrose and $\mathrm{ACME}_{\text {PLUS }}$ Project, "A Systematic Literature Review of Factors Affecting Outcome in Older Medical Patients Admitted to Hospital," Age and Ageing, Vol. 33, No. 2, 2004, pp. 110-115.

http://dx.doi.org/10.1093/ageing/afh036

[28] F. Oyebode, S. Cumella, G. Garden and S. Binyon, "Diagnosis-Related Groups: Implications for Psychiatry," Psychiatric Bulletin, Vol. 14, 1990, pp. 1-3. http://dx.doi.org/10.1192/pb.14.1.1

[29] J. T. English, S. S. Sharfstein, D. J. Scherl, B. Astrachan and I. L. Muszynski, "Diagnosis-Related Groups and General Hospital Psychiatry: The APA Study," American Journal of Psychiatry, Vol. 143, 1986, pp.131-139.

[30] M. Moran, "Hospitals Wait to See New Payment System's Effects," Psychiatric News, Vol. 39, No. 23, 2004, pp. 5-46.

http://psychnews.psychiatryonline.org/newsarticle.aspx?a $\underline{\text { rticleid }=108133 \& \text { RelatedNewsArticles }=\text { true }}$

[31] Feeley \& Driscoll Health Care Services Group, "Psychiatric Hospital Prospective Payment System (PPS)," Feeley \& Driscoll, P.C., Massachusetts.

http://www.fdcpa.com/Healthcare/Psychiatric\%20Hospita 1\%20PPS\%20Final\%20Rule\%20FY07.pdf

[32] M. Lunger, B. Dredge, A. Rose, C. Roebuck, E. Plamper, K. Lauterbach and the Working Group, "Using Diagnosis-Related Groups," European Journal of Health Economics, Vol. 49, 2004, pp. 287-289.

[33] Office of Technology Assessment, "Chapter 4 Effects of DRG Payment on Technological Change in Medicine," In: Diagnosis Related Groups (DRGs) and the Medicare Program: Implications for Medical Technology: A Technical Memorandum, US Congress, Office of Technology Assessment, OTA-TM-H-17, Washington, DC, 1983. 